\title{
ENTRE O ESTADO, A SOCIEDADE E O INDIVÍDUO - UMA REFLEXÃO BIOÉTICA SOBRE NOÇÕES DIVERGENTES DE CONTROLE SOCIAL E A SAÚDE PÚBLICA
}

\section{Among the state, the society and the individual - a bioethics reflection about divergent notions of social control and the public health}

\author{
Paulo Antonio de Carvalho Fortes \\ Faculdade de Saúde Pública da USP, São Paulo, Brasil. \\ pacfusp@usp.br
}

\begin{abstract}
Resumo: O texto pretende trazer uma breve reflexão bioética sobre vertentes da noção de controle social e sua relação com a saúde pública. A visão clássica do controle social que o relaciona a controle da sociedade e do Estado sobre o comportamento dos indivíduos e a noção de controle social institucionalizado, com referência à participação social nos processos decisórios relativos à organização e ao funcionamento da ação do Estado na saúde pública.
\end{abstract}

Palavras-chave: Saúde pública. Bioética. Controle social.

\begin{abstract}
This text aims at bringing about a brief bioethical discussion on divergent ideas of social control and its relationship with public health. The classical view on the social control, which relates it to society and the State control over the individuals behavior, and the notion of institutionalized social control with regard to social participation in decisive processes connected with organization and functioning of the State on public health.
\end{abstract}

Key words: Public health. Bioethics. Social control.

\footnotetext{
A noção de "controle social" tem tido interpretaçōes diversas, complexas e polêmicas na literatura das ciências sociais e no campo da saúde e da bioética. A visão clássica do controle social o relaciona aos vários instrumentos e instituições que a sociedade e o Estado lançam mão para exercer o poder e regular o comportamento dos indivíduos, visando manter a ordem social e o sistema de valores morais prevalentes (ALVAREZ, 2004; LIANOS, 2003).

Porém, mais recentemente, de forma quase diametralmente oposta ao primeiro significado, o termo controle social vem sendo utilizado com
} 
referência a formas de controle da sociedade civil sobre a ação e a organização do Estado e da Administração Pública.

\section{O Controle do Estado e da Sociedade sobre o Indivíduo}

Como instrumento social de regulação do comportamento dos indivíduos, o controle social objetiva a manutenção da ordem social, restringindo comportamentos desviantes da norma. Pode ser compreendido como sendo um conjunto de recursos materiais e simbólicos que a sociedade utiliza para assegurar a conformidade de seus integrantes a um conjunto de valores e regras prevalentes em determinado momento histórico (ALVAREZ, 2004; HORWITZ, 1990).

Nas sociedades pré-modernas as normas morais compartilhadas, mediadas muitas vezes por princípios de natureza religiosa, foram as únicas formas controladoras da ordem social, mediante o escárnio, a sensação do ridículo, a raiva, o temor da divindade e mesmo o recurso à violência. Nas sociedades mais complexas, às normas morais se agregam funções de controle social mais especializadas - as normas jurídicas e a ação de agentes e instituições do Estado.

Os estudos sobre controle social no século XX voltaram-se tanto para a questão dos desvios, da marginalidade, do crime, quanto para a organizaÇão e o funcionamento de organizações complexas, tais como as prisôes, o sistema escolar, os asilos e os hospitais, envolvendo o conhecimento da norma e das relações de poder ocorrentes entre instituições e indivíduos. Nas últimas décadas os estudos e pesquisas sobre controle social vêm ampliando seu campo, aprofundando a reflexão sobre temas como: o controle social exercido sobre o corpo das pessoas, o controle dos processos imigratórios, o papel das novas tecnologias eletrônicas e informacionais e suas conseqüências sobre os indivíduos e grupos populacionais, assim como os controles físico, psíquico e social das ações de saúde pública sobre os indivíduos (FOUCAULT, 2005; LIANOS, 2003; LECORPS \& PATURET, 1999).

Enfim, atualmente as normas morais e as jurídicas, assim como diversas práticas institucionais, exercem um controle social desde o nascimento da pessoa até sua morte, fornecendo padrões do bem e do mal, do certo e do errado, do justo e do injusto, podendo prescrever o que deve ser feito ou o que não deve ser feito. Sua validade moral estaria fundada na pressuposição de que a função primordial do controle social é o bem comum, priorizando o princípio de justiça sobre o da autonomia. Assim, por seu inerente poder 
coercitivo, tende a reduzir a expressão da vontade autônoma do sujeito, limitando as alternativas do agente ou trazendo ameaças de sanção ao indivíduo em estados não desejados por ele.

Pessoa autônoma é a que escolhe livremente entre as alternativas que lhe são apresentadas e decide o que é bom para ela, de acordo com seus valores, expectativas e necessidades, compreendendo as conseqüências de suas escolhas. Contudo, a autonomia completa é um ideal, pois nas relações humanas e na convivência social existem graus variados de controle, o que náo significa que o homem seja um ser pré-programado, que tenha seu destino determinado totalmente por forças sócio-culturais ou mesmo por condicionantes psíquicos.

Aceitando que a ação autônoma requer que o indivíduo possa se mover dentro de uma margem própria de decisão e de ação, pois se não pode escolher o que lhe acontece, mas pode escolher o que fazer diante da situação que lhe é apresentada - como afirmou o filósofo espanhol Savater - quais seriam as características do controle social que podem ser imputadas como restritoras da autonomia individual? (SAVATER, 1993).

Vivemos em uma época histórica caracterizada pela existência de estranhos morais, ou seja, pessoas que não compartilham de regras morais de evidencia e que acatem a resolução de possíveis conflitos por argumentação racional ou por intermédio de pessoas ou instituiçôes com autoridade para tanto (ENGELHARDT JR, 1995). Assim, é difícil o consenso sobre os pontos em que o controle social fosse validado eticamente por garantir a convivência social, o bem comum. Para Engelhardt, o único princípio possível a ser acordado entre todos seria o do respeito mútuo, mediado pela permissão, pelo consentimento. Se medidas de controle social, impostas pelos mecanismos democráticos, são aceitas pela sociedade, isto é, entendendo-se que são permitidas pelo contrato social vigente, que os cidadãos deram seu consentimento, podem também ser consideradas como moralmente válidas.

Mas, o controle social também seria moralmente validado quando se caracteriza pelo paternalismo estatal ou societário incidindo sobre o indivíduo? Paternalismo aqui compreendido como sendo a interferência sobre a vontade de pessoa autônoma, mediante ação justificada exclusivamente pelo bem estar, necessidades, interesses da pessoa que está sendo coagida.

A esse respeito a reflexão bioética sobre o controle social nos remete ao pensamento exposto há dois séculos atrás por John Stuart Mill (1806-1873). O filósofo inglês, autor do clássico On liberty, defendia que a interferência da sociedade e do Estado sobre a liberdade de qualquer um de seus mem- 
bros seria válida quando destinada a prevenir danos a outros indivíduos ou à própria coletividade, visando o bem comum, não o sendo quando dirigida ao benefício do próprio coagido (MILL, 1985).

Filósofos contemporâneos, de orientação liberal, como Nozick, também são contrários a uma ação paternalista, entendendo que a convivência humana deva ter pouca mediação obrigatória do coletivo sobre o individual. Em seu livro Anarquia, Estado e utopia, de 1974, defende a tese do Estado Mínimo, pois para ele a intervenção estatal só é justa quando se limita à proteção dos direitos individuais contra suas violações por parte de terceiros, garantindo o princípio da segurança (NOZICK, 1994). Nessa linha de pensamento Engelhardt expressa que não deveríamos fazer ao outro aquilo que ele não faz consigo mesmo; somente deveríamos fazer aquilo que com ele tenha sido contratado para ser feito (ENGELHARDT JR., Op.cit.).

No entanto, observa-se que a aceitação de medidas paternalistas estatais varia dependendo da cultura de cada sociedade e de sua eficácia, por exemplo, medidas de saúde pública voltadas contra aspectos de morbidade ou de mortalidade prevalentes. É o caso do uso de cinto de segurança nos veículos e do capacete para os que conduzem motocicletas, impostos a todos, independentemente da sua aceitação individual (FORTES, 2000).

\section{A Saúde Pública e o Controle Exercido sobre os Indivíduos}

O objeto da saúde pública é o processo saúde-doença da coletividade visando promover, proteger e restaurar a saúde dos indivíduos e da coletividade, e obter um ambiente saudável, por meio de ações e serviços resultantes de esforços organizados e sistematizados da sociedade. Portanto, entre os fundamentos éticos que norteiam as ações coletivas de saúde estão os princípios da beneficência, da não maleficência, do respeito à autonomia individual, assim como o princípio da justiça distributiva e da equidade.

As ações de saúde pública se exercem em condições em que não exista possibilidade de uma intervenção eficaz por parte da ação individual, seja pela falta ou controle de informaçôes necessárias que não dominam, seja pela carência de possibilidade de intervenção individual sobre os fatores coletivos que produzem os riscos de adoecer (LECORPS \& PATURET, 1999).

As medidas de saúde pública que restringem ou limitam liberdades e direitos individuais, relacionadas, por exemplo, às vigilâncias - sanitária e epidemiológica - podem ser eticamente justificadas pelo princípio da não maleficência, por prevenir danos a terceiros e à coletividade. Quando um 
agente sanitário interdita um estabelecimento comercial ou industrial ou apreende um animal doméstico suspeito de estar contaminado por um agente infeccioso potencialmente disseminador para a coletividade, ele está restringindo o direito de propriedade, o direito de a pessoa querer ou não querer possuir um determinado bem, porém fundamentado pelo bem estar da coletividade.

Essa mesma fundamentação é válida para medidas de vigilância epidemiológica, como a notificação compulsória de doenças, que limitam o princípio da privacidade das informações, assim como no caso da necessidade de manter uma pessoa em isolamento ou em quarentena, restringindo a liberdade de locomoção da pessoa contra sua vontade.

O princípio da não maleficência do coletivo também pode justificar que o controle social do Estado torne obrigatória a vacinação de crianças e adolescentes contra determinadas moléstias infecto-contagiosas, mesmo contra a vontade paterna. Os pais ou responsáveis passam a ter o dever de vacinar as crianças e os adolescentes, não somente em virtude da proteção individual destes, mas também porque uma pessoa infectada pode ser um veículo de contaminação de terceiros, resultando em danos para a coletividade.

Neste sentido, é possível entender-se que as medidas de controle social que proíbem fumar em edifícios públicos, assim como a venda e controle do consumo de álcool em rodovias também são validados pelo princípio da beneficência e da não maleficência da coletividade. Nesse sentido, em alguns municípios brasileiros, depois de determinado horário noturno, há também o impedimento da venda de bebidas alcoólicas, visando, principalmente, a diminuição de brigas e conflitos que resultem em lesões físicas e homicídios causados pelo excesso do consumo.

Mas, nem sempre as medidas de saúde pública trazem obrigações orientadas pelo interesse da coletividade. Em nosso cotidiano, ocorrem e são aceitas ações de saúde pública, de caráter obrigatório, que podem contrariar a liberdade pessoal de decidir, e que não se fundamentam no princípio da não maleficência da coletividade, mas sim na existência de benefícios diretos para o bem-estar ou a saúde das pessoas que deverão ser submetidas a elas, contrariando as linhas éticas anti-paternalistas defendidas tanto por Stuart Mill como por Nozick e Engelhardt. Seria o caso, se fosse legalmente imposta às pessoas a realização de exames diagnósticos pré-natais para a detecção de condições desfavoráveis ao feto e à mãe, por exemplo, o teste de HIV.

Nas últimas décadas o controle social vem sendo dirigido a estilos de vida considerados não-saudáveis, mediante a imposição de condutas "poli- 
ticamente corretas". Instaurou-se um processo de "culpabilização da vítima", promovido tanto pelos profissionais de saúde quanto pelo público em geral e os meios de comunicação, processo que tende a desfavorecer as pessoas que levam estilos de vida considerados não-saudáveis, penalizando-as por não terem tomado "melhor conta de sua saúde", por não terem preservado sua "boa saúde" (BERLINGUER, 1996).

Entre as pessoas que estariam levando estilos de vida tidos como nãosaudáveis estão os fumantes, os alcoólatras, os usuários de drogas ilícitas, os comedores de excesso de sal ou gordura, as pessoas de vida sedentária e as que realizam sexo sem utilização de preservativos para evitar doenças sexualmente transmissíveis. Também são relacionados como tendo estilos de vida não-saudáveis, os praticantes de determinadas formas de lazer que envolvem significativos riscos à própria vida, tais como as pessoas que praticam alpinismo, skate e asa-delta.

O controle social sobre comportamentos não-saudáveis é defendido por se entender que possam trazer não somente prejuízos individuais, mas também efeitos deletérios para a sociedade, como o aumento de custos para os sistemas de saúde. Por exemplo, em caso de necessidade de assistência à saúde por parte de pessoas com esses estilos de vida, tanto o sistema público de saúde, subsidiado por impostos ou por contribuições para a seguridade social, quanto os sistemas privados, cujo financiamento cabe ao indivíduo, à família ou às empresas, se veriam comprometidos material e financeiramente.

Todavia, cabe concordar com Wickler e Crawford, que desde os anos 1970, alertavam que a responsabilização individual por condutas não-saudáveis tenderia a desviar a discussão sobre outros fatores sociais, ambientais e econômicos e sobre as condições de trabalho, ou seja, fatores que influem no processo saúde-doença (WICKLER, 1978; CRAWFORD, 1977).

Também existem sérias dificuldades na avaliação e na determinação de quais são os estilos de vida que são frutos de manifestação de real autonomia individual, quando atualmente há uma tendência, ocasionada pelas recentes descobertas científicas, ainda que discutíveis, é verdade, sobre as bases genéticas para a utilização pessoal do fumo, da obesidade e de outras formas de comportamento, como tendências anti-sociais. Assim, poderiam ser culpabilizadas as pessoas que se encontram em condiçôes precárias de saúde, derivadas de estilos de vida não-saudáveis, mas que não assumiram livre e esclarecidamente seus comportamentos? Por exemplo, os profissionais que desempenham certas atividades junto ao público e que passam a 
ser "fumantes passivos", desenvolvendo patologias do trato respiratório, ocasionadas por comportamentos dos fumantes.

Pode ser ainda lembrado o incremento do número de casos clínicos de lesões de esforço repetitivo devido à alta freqüência do uso de computadores pessoais nas últimas décadas. Se aceitássemos que as pessoas que trabalham em setores da informática e os bancários, manipulando horas e horas seus teclados, não desconhecem os possíveis riscos a que estão expostos, deveríamos considerar que sejam penalizadas ao adquirir uma Lesão de Esforço Repetitivo, por não se proteger adequadamente?

Cabe novamente indagar quando ações de saúde pública podem ser compreendidas como persuasivas ou coativas e quais os limites do controle social que são validados moralmente?

Não é fácil responder a esta questão, pois nossa época é permeada de grandes e às vezes intransponíveis dificuldades para resolver controvérsias morais. Na "pós-modernidade", a sociedade não aceita a existência de deveres e princípios absolutos como outrora, caracterizando-se pela existência de um pluralismo de valores morais que muitas vezes se tornam incompatíveis entre si, dificultando sobremaneira estabelecer consensos sobre as bases aceitáveis de um controle social que interfira na vida e nas decisões das pessoas (ENGELHARDT Jr., Op.cit.).

\section{O Controle da Sociedade Civil sobre o Estado: o controle social institucionalizado}

Diferentemente do significado da noção de controle social como ação da sociedade e do Estado sobre o individuo, nas últimas décadas do século passado começou-se a utilizar o termo controle social com referência à participação social na gestáo pública e na prestação de serviços públicos, atuando nos processos decisórios relativos à organização e ao funcionamento do aparelho de Estado, objetivando adequar a ação estatal às necessidades da coletividade.

Tal tema interessa à reflexão da bioética social, que se preocupa com questôes como justiça, acesso aos sistemas sociais, equidade e solidariedade, pois o controle social institucionalizado, conformando uma nova relação entre Estado e sociedade civil, efetua-se no exercício de sua vontade autônoma, sendo seus membros aceitos como cidadãos, tendo direitos e deveres perante o Estado. Portanto, o controle social sobre a ação estatal visa modificar ou alterar as condições vigentes, permitindo aos cidadãos participar da gestão e/ou exercer a fiscalização, voltados para a eficácia dos direitos da cidadania. 
Ressalte-se que a noção de controle social institucionalizado se diferencia da participação comunitária que muitas vezes é requerida para auxílio à atividade estatal, sem que se dê a participação dos cidadáos na tomada de decisão, como ocorre em campanhas de vacinação, de combate a doenças infecciosas como a dengue e a malária. Também não se deve confundir com formas de participação comunitárias voltadas principalmente ao trabalho voluntário, por exemplo, mediante grupos de auto-ajuda (ORGANIZACIÓN PANAMERICANA DE LA SALUD, 1995).

A ampliação do controle social nas políticas públicas é compreendida como uma forma de democracia participativa ou democracia direta, diferenciando-se da democracia representativa parlamentar, a qual vem se desenvolvendo conjuntamente à evolução de formas denominadas de terceiro setor e do descrédito crescente com as instituições políticas e a democracia parlamentar (BOGUS, 2005; ORGANIZACIÓN PANAMERICANA DE LA SALUD, 1993). A participação se dá de forma direta ou mediante representação, atuando nas instâncias do aparelho de Estado - órgãos, agências ou serviços públicos responsáveis pelas políticas públicas. Assim, podemos entender o controle social como sendo um instrumento da sociedade para o acompanhamento, monitoramento, fiscalização e avaliação das ações implementadas pelo poder público.

Jacobi, citado por Bogus, afirma que a concepção de participação social, enquanto controle social da ação estatal, tem possibilitado a presença de novos atores sociais, principalmente os provenientes de camadas populares mais desfavorecidas, atuando mediante movimentos sociais urbanos reivindicatórios de bens e serviços públicos por terra e moradia. Também foram incorporadas parcelas dos denominados "novos movimentos sociais", em luta pelo reconhecimento de direitos sociais relativos a raça, gênero, sexo, qualidade de vida ou preservação do meio ambiente (BOGUS, 2005). A presença da pluralidade das formas associativas populares na arena decisória das políticas públicas pode levar a uma maior representatividade dos diversos e diferenciados interesses e valores morais existentes na sociedade, tendo potencial expressivo para promover o empoderamento dos participantes e da comunidade, pelo processo de mobilizações e práticas destinadas a promover e impulsionar os grupos sociais no sentido de melhora da vida e visão crítica da realidade social (GOHN, 2004).

Segundo Oliveira, o controle social institucionalizado pode ser entendido no contexto do fenômeno político da societal accountability: 
"(...) espaço político onde um ou vários atores sociais podem cobrar publicamente de outros (instituições, organizações empresariais, autoridades ou das lideranças políticas) comportamentos geradores de transparência e de adequação de seus atos às expectativas de interesse individual, público e/ou coletivo, de acordo com as normas e funçôes previstas ou publicamente reconhecidas onde atuam" (OLIVEIRA, 2004).

\section{Controle social como forma de exercício na redistribuição do poder estatal}

Ao contrário da noção de instrumento restritor da atividade do indivíduo, o controle social como mecanismo de participação social nas atividades estatais pode ampliar a autonomia individual e a coletiva nas decisôes sobre as políticas públicas. Agindo nas decisões das políticas sociais, tem potencial para fortalecer a auto-estima dos agentes sociais e atenuar as iniqüidades existentes em nosso meio cultural e político, ampliando as possibilidades do estabelecimento de políticas sociais orientadas pelos princípios éticos da justiça, da equidade e da solidariedade.

O controle social institucionalizado traz a presença ao processo decisório dos vários atores e segmentos sociais que possuem menor poder de pressão política junto aos mecanismos formais da democracia representativa. Sua atuação ocorre dentro de um contexto dinâmico de transformações sociais e econômicas característicos das duas últimas décadas, que afeta o meio ambiente, as relações de trabalho, assim como as organizações de cuidados de saúde (FORTES \& ZOBOLI, 2005).

Ressalte-se também que a crise social das últimas décadas tem resultado em aprofundamento das desigualdades sociais, em maior distanciamento entre os ricos e os pobres, assim como uma diminuição das formas solidárias de ação. Assim sendo, esta forma de participação social ocorre dentro de um contexto de transformações importantes nas relações de trabalho, com o incremento do mercado de trabalho informal, a terceirização e a defasagem na qualificação de grandes contingentes de pessoas para um mercado de trabalho dominado pela necessidade de especialização e pelo rápido avanço tecnológico (BOFF, 2003).

Também se dá em um ambiente de pluralidade de valores que fundamentam as diversas alternativas teóricas que procuram interpretar o princípio ético da justiça, orientador da organização dos sistemas sociais.

A orientação liberal, que tem sido hegemônica, entende que o princípio ético fundamental a ser observado na distribuição social de recursos é o respeito à liberdade da pessoa humana de tomar decisões que afetem sua 
vida, o respeito a se fazer escolhas. O princípio ético da justiça é compreendido como sendo o da liberdade contratual. Ao Estado se exige somente ser o garantidor da ordem, da segurança, das liberdades individuais e do direito à propriedade. Não lhe é demandada a resolução de necessidades individuais, nem requerida a implementação dos direitos sociais, entre eles o da saúde. Em um contexto de pensamento liberal, devido ao papel desempenhado pelo Estado, o controle social tem dimensões diferenciadas quando comparado ao efetivado junto a sistemas sociais que se fundamentam pelas necessidades individuais.

Teorias que se baseiam no atendimento das necessidades das pessoas propugnam que o Estado, mediante a implementação de políticas públicas, deva intervir para garantir a justiça distributiva e minimizar os efeitos das loterias biológica e social. Em sistemas sociais orientados pelas necessidades, a natureza do controle social institucionalizado apresenta um campo de ação mais amplo devido ao alcance e dimensão das políticas sociais a serem implementadas (BERLINGUER, 1996; SPINSANTI, 1988).

\section{Instrumentos do controle social voltados à saúde pública}

A experiência brasileira de órgãos colegiados junto à administração pública com a participação da sociedade civil se ampliou a partir da década de 1990 após a promulgação da atual Constituição. No campo da saúde constituíram-se as Conferências de Saúde e os Conselhos de Saúde. As Conferências de Saúde, regulamentadas pela Lei $n^{\circ} 8.142 / 1990$, têm sua realização como obrigatória por todas as esferas de governo (municipal, estadual e federal), com periodicidade mínima de quatro anos. Constituem-se em instâncias responsáveis pela avaliação da situação de saúde e pela proposição de diretrizes para a formulação das políticas de saúde.

A lei também criou a obrigatoriedade de organização e funcionamento de Conselhos de Saúde em todos os níveis de governo, tendo caráter permanente e deliberativo. São compostos por representantes do Governo, prestadores de serviços públicos e privados, profissionais de saúde e usuários. As competências legais estabelecidas para os Conselhos de Saúde passam a permitir o exercício da autonomia e da responsabilidade dos principais interessados no sistema de saúde ao poderem atuar na formulação e no controle da execução da política de saúde, inclusive em seus aspectos econômicos e financeiros. Tornaram-se atribuições dos Conselhos: traçar diretrizes, aprovar os planos de saúde, controlar e fiscalizar a movimentação de recursos repassados às Secretarias de Saúde ou Fundos de Saú- 
de. Além dessas competências, podem exercer o papel de instrumentos adequados para o direcionamento de reclamações de setores desorganizados da sociedade, de publicização e transparência da política pública (FORTES, 1997).

A motivação do legislador à participação dos diversos segmentos sociais tornou a representação dos usuários nas Conferências e nos Conselhos de Saúde paritária em relação ao conjunto dos demais segmentos - prestadores de serviços, trabalhadores de saúde e Governo. A representação dos usuários detém cinqüenta por cento dos assentos no Conselho, sendo que a outra metade é dividida para a representação governamental, dos prestadores de serviços de saúde e dos trabalhadores de saúde.

Um fenômeno específico da área de saúde no Brasil, foi o desenvolvimento de formas organizacionais da sociedade civil agindo em defesa de portadores de patologias crônicas, reivindicando acesso à terapêuticas, como hemodiálise para renais crônicos e medicamentos essenciais para pessoas com HIV/Aids, talassemia, anemia falciforme, entre outras patologias, que têm participado de forma expressiva nos colegiados do controle social institucionalizado nas três esferas de governo.

\section{O controle social institucionalizado e a ação dialógica}

Os mecanismos de controle social institucionalizado devem possibilitar a ampliação da ação dialógica, envolvendo os diversos interessados, explicitando conflitos de interesses e valores, valorizando a existência do outro, buscando a constituição de possíveis consensos. Pode-se dizer que a aceitação como interlocutores válidos de todos os segmentos sociais interessados em um determinado campo social, tal qual o campo da saúde implica que estes devem ser ouvidos e ter poder para influenciar na tomada de decisão para os programas, projetos e políticas sociais. Neste sentido, é necessário que sejam aceitos os pressupostos definidores de uma sociedade pós-convencional, defensora de valores universais garantindo, assim, a ocorrência de situações de simetria para se chegar a acordos satisfatórios para os diversos segmentos representados (CORTINA \& MENENDEZ, 2005).

Todavia, há os que defendem a tese de que a participação social nas decisões das políticas sociais ainda é bastante fragilizada devido aos distintos níveis de conhecimento dos representantes dos segmentos populares sobre as questões de natureza técnica, quando comparados com o conhecimento e a informação dos profissionais de saúde e administração. Assim não se teria um "discurso autêntico", pois as relações não se dariam entre iguais, 
estando o poder do conhecimento ainda concentrado nos técnicos e profissionais (OLIVEIRA, 2004; PUPO, 1999; PINHEIRO \& DAL POZ, 1995).

Se isso se configura como uma situação verídica, pode-se conceber que no denominado controle social institucionalizado, a manifestação de uma real decisão autônoma por parte dos setores sociais envolvidos, principalmente dos não-técnicos, estaria comprometida. Assim, o desafio é estabelecer mecanismos de diálogo eficazes dentro de uma composição de atores sociais que representem o pluralismo de valores existentes em nossa época. Há preocupações por parte dos estudiosos do controle social institucionalizado sobre se as condiçôes em que se realiza são propícias à existência de uma "situação ideal de fala", conforme entendido pela teoria ética defendida por Habermas (TUGENDHAT, 2000).

\section{Consideração Final}

Ao se conhecer as divergentes noções do controle social e suas incidências sobre o campo da saúde pública, compreende-se a importância da reflexão bioética em fornecer fundamentos para sua validade. Apesar de ser uma tarefa difícil, há de se concordar com Cortina e Menendez (2005), Boff (2003) e Lepargneur (1996), quando afirmam que a discussão bioética pode auxiliar na maximização do consenso sobre normas práticas que dizem respeito à vida e à saúde da espécie humana, construindo a convivência da vida em sociedade.

\section{Referências Bibliográficas}

ALVAREZ, MC. Controle social: notas em torno de uma noção polêmica. São Paulo em Perspectiva 18(1), 2004.

BERLINGUER, G. Ética da saúde. São Paulo: Hucitec; 1996.

BOFF, L. Ethos mundial: um consenso mínimo entre os humanos. Rio de Janeiro: Sextante, 2003.

BOGUS, CM. Os Conselhos de Saúde e o fortalecimento da democracia brasileira. O Mundo da Saúde 29(1): 41-48, 2005.

CORTINA, A \& MENENDEZ, E. Ética. São Paulo: CUSC/Loyola, 2005.

CRAWFORD, R. You are dangerous to your health: the ideology and politics of victim blaming. International Journal of Health Services 7(4):663-80, 1997.

ENGELHARDT Jr., T. Fundamentos de bioética. São Paulo: CUSC/Loyola, 1995. 
FORTES, PAC. \& ZOBOLI, ELCP Os princípios do Sistema Único de Saúde - SUS potencializando a inclusão social na atenção à saúde. O Mundo da Saúde 29(1): 20-25, 2005.

FORTES, PAC. Bioética e saúde pública: tópicos de reflexão para a próxima década. O Mundo da Saúde 24 (1): 31-38, 2000.

$5(1): 71-6,1997$

A ética do controle social na saúde e os conselhos de Saúde. Bioética

FOUCAULT, M. Vigiar e punir. 30ª edição. Petrópolis: Vozes, 2005.

GOHN, MG. Empoderamento e participação da comunidade em políticas sociais. Saúde e Sociedade 13(2): 20-31, 2004.

HORWITZ, AV. The logic of social control. New York: Plenum Press, 1990.

LIANOS, M. Social control after Foucault. Surveillance and society 1(3) 412-430, 2003.

LECORPS, P \& PATURET, JB. Santé publique: du biopouvoir à la démocratie. Rennes: École Nationale de Santé Publique, 1999.

LEPAGNEUR, H. Bioética, novo conceito: a caminho do consenso. São Paulo: CEDAS/ Loyola, 1996.

MILL, JS. On liberty. London: Penguin Books, 1985.

NOZICK, R. Anarquia, estado e utopia. Rio de Janeiro: Jorge Zahar Editora, 1994.

OLIVEIRA, VC. Comunicação, Informação e Participação Popular nos Conselhos de Saúde. Saúde e sociedade 13(2): 56-69, 2004.

ORGANIZACIÓN PANAMERICANA DE LA SALUD. La participación social en el desarrollo de la salud: experiencias latinoamericanas. Washington: OPS, 1995

ORGANIZACIÓN PANAMERICANA DE LA SALUD. La participación social en el desarrollo de la salud. Washington: OPS, 1993.

PINHEIRO, R, \& DAL POZ, MR. Democratizaçāo e controle social na saúde: análise do Conselho Estadual de Saúde do Rio de Janeiro. Rio de Janeiro: Universidade Estadual do Rio de Janeiro/ Ministério da Saúde, 1995

PUPO, TRGB. Participação dos Conselhos Municipais de Saúde no processo decisório de formulaçāo e implementaçāo das políticas de saúde: estudo de caso em dois municípios em gestão semiplena. Dissertação de Mestrado, Faculdade de Saúde Pública, Universidade de São Paulo, 1999.

SAVATER, F. Ética para meu filho. São Paulo: Martins Fontes, 1993.

SCHOPP, RF. Behavior control. In: REICH, WT. editor. Revised edition. Encyclopedia of bioethics [CD ROM]. New York: Macmillan Library Reference, 1995.

SPINSANTI, S. Ética biomédica. São Paulo: Paulinas, 1988.

THUGENDHAT, E. Lições sobre ética. $4^{\mathrm{a}}$ ed. Petrópolis: Vozes, 2000.

WICKLER, D. Who should be blamed for being sick? Health Education Quarterly; 14 (1): 11-25, 1978 . 